(2) Open Access Full Text Article

REVIEW

\title{
Assessing chronic wound perfusion in the lower extremity: current and emerging approaches
}

This article was published in the following Dove Press journal:

Chronic Wound Care Management and Research

27 October 2015

Number of times this article has been viewed

\author{
Kevin Y Woo' \\ Timothy M Brandys ${ }^{2}$ \\ Joseph A Marin' \\ 'School of Nursing, Faculty of \\ Health Sciences, Queen's University, \\ Kingston, ${ }^{2}$ Department of Surgery, The \\ Ottawa Hospital, Ottawa, ON, Canada
}

Correspondence: Kevin Y Woo School of Nursing, Faculty of Health Sciences, Queen's University,

92 Barrie Street, Kingston, ON, Canada K7L 3N6

Tel + I 6I3 5336000 ext 74747

$\mathrm{Fax}+\mathrm{I} 6135336770$

Email kevin.woo@queensu.ca

\begin{abstract}
Current evidence suggests that vascular and wound bed perfusion assessment should be integral to the care of people with chronic wounds in the lower extremities. Peripheral artery diseases can be insidious, with many affected individuals unaware of circulation issues and failing to seek medical help until they develop foot ulcers, gangrene, and other related complications. Measuring tissue perfusion is a useful diagnostic marker for chronic wounds and may help determine a wound's potential for healing. A complete patient history and physical examination is imperative to help determine the correct diagnosis of lower extremity ulcers. This article aims to discuss current and emerging wound perfusion assessment techniques, including ankle-brachial index, toe-brachial index, transcutaneous oxygen pressure, near-infrared spectroscopy, digital subtraction angiography, magnetic resonance angiography, computed tomographic angiography, and indocyanine green angiography.
\end{abstract}

Keywords: tissue perfusion, peripheral arterial disease, oxygen, wound healing

\section{Introduction}

Vascular and wound bed perfusion assessment should be integral to the care of people with associated atherosclerotic risk factors and chronic wounds in the lower extremities. Peripheral artery diseases (PADs) can be insidious, with many affected individuals unaware of circulation issues and failing to seek medical help until they develop foot ulcers, gangrene, and other related complications. ${ }^{1}$ With an aging population and growing prevalence of complex comorbidities, these non-healing wounds are recognized as a burgeoning health problem placing significant burden on the affected individuals and the health care system. ${ }^{2,3}$ There are a number of methods to assess for perfusion and wound-tissue oxygen balance that can be integrated into clinical practice. Accurate assessment will help determine healing potential and trigger early intervention to correct wound perfusion, such as hyperbaric oxygen therapy and revascularization. This article aims to discuss current and emerging wound perfusion assessment techniques that can be utilized for the advancement of patient care and wound-healing outcomes.

\section{Chronic wounds and perfusion}

Cells and tissues are dependent on the vasculature for transport of oxygen and other essential nutrients. Disturbances in macro- or microvascular supply, such as ischemia (low perfusion pressure) and hypoxia (low oxygen content), can have profound effects on local tissue viability and repair. Adequate tissue perfusion and oxygenation is particularly relevant in healing tissue due to an increased energy demand for 
reparative processes. ${ }^{4} \mathrm{An}$ expanding base of experimental and clinical investigation, as well as advancements in techniques to obtain accurate wound-tissue oxygen measurements, has begun to reveal that sufficient tissue oxygenation is critical for nearly all wound-healing processes. Emerging evidence for oxygen's central role in wound healing includes: ${ }^{5-13}$

- Antimicrobial action

- Oxygen levels have a positive prevention effect on wound infection rates

- Stimulation of selective leukocyte microbial killing in wound bed

- Insufficient oxygen may lead to an increased bacterial load

- Cell metabolism

- Essential in production of high-energy metabolites (ATP) required for reparative processes

- Collagen synthesis

- Involved in the hydroxylation of proline and lysine in procollagen that is crucial for collagen maturation; insufficient oxygen may lead to poor collagen deposition

- Supports cell motility and extracellular matrix formation

- Neovascularization

- Induces angiogenesis, which restores tissue perfusion, reestablishes microcirculation, and increases oxygen tension to normal levels

- Oxygen induces vascular endothelial growth factor mRNA levels in endothelial cells and macrophages in vivo

- Supplemental oxygen administration has been shown to sustain and accelerate vessel growth

- Cell differentiation

- May facilitate wound contraction by triggering the differentiation of fibroblasts to active contracting myofibroblasts

- Increases keratinocyte differentiation, migration, and reepithelialization.

Chronic wounds are notably hypoxic, with transcutaneous oxygen tensions $\left(\mathrm{TcPO}_{2}\right)$ measured from $5 \mathrm{mmHg}$ to $20 \mathrm{mmHg}$, compared to control tissue values of $30 \mathrm{mmHg}$ to $50 \mathrm{mmHg}$. ${ }^{14}$ Temporary hypoxia after injury is a necessary trigger for the initial phases of wound healing, stimulating processes such as the release of growth factors and angiogenesis. ${ }^{13}$ However, chronic or prolonged periwound and wound bed hypoxia delays healing due to the imbalance between decreased oxygen delivery/availability and increased tissue demand during recovery from tissue injury. Chronic low $\mathrm{TcPO}_{2}$ and perfusion pressure may be associated with accumulation of necrotic tissue and poor formation of granulation tissue, ${ }^{15}$ and may contribute to the accumulation of harmful substances in the periwound microenvironment such as lactic acid (from hypoxia-induced anaerobic metabolism) that are further deleterious to wound healing.

\section{Pathologies related to poor oxygen perfusion}

Multiple pathologies are capable of impairing wound-tissue oxygen balance. PAD is one of the leading conditions that can alter perfusion and thereby increase susceptibility to localized tissue ischemia, contributing to delayed healing of lower extremity ulcers. ${ }^{16} \mathrm{PAD}$ is primarily caused by progressive atherosclerotic changes in the arteries reducing normal blood flow to the lower extremities. It is thought to affect approximately $4 \%$ of the population over the age of 40 years and $20 \%$ over 75 years or an estimated 25 million individuals in North America and Europe. ${ }^{17}$ If severe arterial disease is left untreated, insufficient oxygen and nutrients to the tissue could result in complications such as ulceration, gangrene, and eventually amputation. Several studies demonstrate that enhancing wound bed perfusion and tissue oxygenation improves wound healing and reduces bacterial colonization. ${ }^{10}$ Revascularization is now considered a standard therapeutic option for individuals with severe PAD and chronic leg ulcers to facilitate an increase in localized blood flow and oxygen delivery. Diabetes causes significant and extensive structural changes in the vascular system, increasing the risk of developing atherosclerosis (large- and medium-sized arteries) and inducing a specific lesion in microcirculation (small vessels). Hyperglycemia is responsible for the excess production of reactive oxygen species that damage and interfere with normal endothelial functions. ${ }^{13}$

Lifestyle or exogenous factors causing insufficient perfusion, vasoconstriction, or damage to the microvasculature can also result in poor wound healing. ${ }^{18}$ Smoking is known to increase the risk of heart and vascular disease and has been shown to have a negative impact on wound healing via several mechanisms, notably the creation or worsening of wound hypoxia. ${ }^{19}$ Components of cigarette smoke, such as the triad of nicotine, carbon monoxide, and hydrogen cyanide, can interfere with oxygen supply by inducing tissue ischemia via vasoconstrictive effects and impair cellular oxygen metabolism. ${ }^{13}$ Obesity can produce wound-healing complications as a result of relative hypoperfusion and ischemia in the subcutaneous adipose tissue. Increased wound tension in obese individuals may lead to increased tissue pressure and a subsequent reduction in microperfusion and 
availability of oxygen to the wound. ${ }^{13}$ Sedentary habits or immobility can cause sustained external pressure, leading to local skin ischemia and pressure ulcer formation. Chronic physiologic stress and vasoconstricting medications have also shown relevance to tissue perfusion, oxygen delivery, and wound healing.

The identification and management of patients with poor perfusion often presents as a challenge for both the patient and the practitioner. Currently, chronic wounds consist of $98 \%$ of all lower extremity wounds. ${ }^{1}$ More so, the common venous and diabetic etiologies associated with lower extremity wounds have been shown to also have an arterial component. ${ }^{2,3}$ However, early diagnosis is difficult because many patients with arterial disease may remain asymptomatic for months or years until they develop leg ulcers. ${ }^{4}$ Poor vascular supply to the wound results in poor cellular function and senescence. ${ }^{5}$ Many clinics are dependent on simple assessment observations to identify arterial wounds, such as pain, recurrent slough, or punched-out borders. Others have noninvasive arterial study devices, which can more accurately define the patient's perfusion status. Selecting an ideal device to complete a perfusion assessment depends on the goals of the practitioner. While most technologies are designed to provide an estimation of the arterial flow to the extremity, a paucity of research is available to determine perfusion at or around the wound-tissue.

\section{Clinical assessment}

Treatment of chronic wounds requires a systematized approach under the tenets of wound bed preparation, which highlights the importance of optimizing perfusion and correcting underlying pathologies prior to local wound care. A complete patient history and physical examination is imperative to help determine the correct diagnosis of lower extremity ulcers. One of the most common and earliest manifestations of PAD is intermittent claudication, described as pain in a lower extremity muscle group (buttock, thigh, or calf), that is elicited by exertion and relieved within a few minutes of rest. However, only $10 \%-30 \%$ of individuals with PAD complain of claudication. ${ }^{20}$ In other words, the majority of people $(>50 \%)$ with this condition may remain asymptomatic without any clinically obvious signs or symptoms for a relatively long time. The Edinburgh claudication questionnaire (ECQ) is a validated tool that consists of six questions to measure symptoms of PAD. ${ }^{21}$ The questions are:

1) Do you get pain or discomfort in your legs when you walk? 2) Does this pain ever begin when you are standing still or sitting? 3) Do you get it when you walk uphill or hurry? 4) Do you get it when you walk at an ordinary pace on the level? 5) What happens to it if you stand still? 6) Where do you get this pain or discomfort?

The ECQ has $91.3 \%$ sensitivity and $99.3 \%$ specificity in detecting claudication in the general population, compared with the diagnosis of PAD made by clinical examination. Positive predictive value (PPV) and negative predictive value (NPV) for the ECQ have been documented to be $100 \%$ and $81 \%$, respectively. ${ }^{21}$

To obtain a comprehensive assessment of pain, multidimensional measurements are available to evaluate the many facets of pain and its impact on daily functioning, mood, social functioning, and other aspects of quality of life. The key questions to ask about pain can be remembered by PQRST:

- $\quad \mathrm{P}$ - provoking and palliating factors: What makes your pain worse? What makes your pain better (eg, keeping feet warm; putting feet in dangling position and warm weather may alleviate pain, while walking and exposure to cold weather may exacerbate pain)?

- Q-quality of pain: What does your pain feel like? Descriptors, such as burning, electrical shocks, pricking, and tingling pins, are often used to describe neuropathic pain that is common in people with PAD and/or diabetes.

- $\mathrm{R}$-regions and radiation: Where is the pain and does the pain move anywhere (eg, in and around the wound, the wound region, unrelated)? Patient with critical ischemic leg may complain of sudden onset with pain starting off distally, progressing proximally, and increasing in severity over time.

- $\mathrm{S}$ - severity or intensity: How much does it hurt on a scale of $0-10$ with 0 representing no pain and 10 representing pain as bad as it could possibly be?

- T - Timing or history: When did the pain start? Is it present all the time? A pain diary may help to map out the temporal pattern of pain (eg, the pain worsens at night). The peripheral artery questionnaire (PAQ) is a qualityof-life measure specifically designed for people with PAD. ${ }^{22}$ The questionnaire consists of 20 items to evaluate patients' physical limitations, symptoms, social function, treatment satisfaction, and quality of life. The PAQ is reliable with Cronbach's alpha $=0.80-0.94 .{ }^{22}$ Patients who had undergone revascularization achieved a significant improvement in PAQ score substantiating the sensitivity of the PAQ to change. ${ }^{22}$ Construct validity has been established by demonstrating correlations with other measures of patient health status. 
With chronic hemodynamic and metabolic modifications, patients with arterial disease may exhibit trophic changes consistent with chronic ischemia. The skin may become pale, bluish, or dusky in color; dry; thin; hairless; shiny; and cool to touch, and there can be thickening of the nails and alterations in the foot structure. ${ }^{23}$ Ischemic feet may appear erythematous, especially when the feet are arranged in dependent positions, also known as dependent rubor. This finding can sometimes be confused with cellulitis or gout. Abnormal capillary refill time (likelihood ratio [LR], 1.90; 95\% confidence interval [CI], 1.20-3.20) is another clinical maneuver that can be incorporated into routine assessment of patients' feet. ${ }^{24}$ Ulcers associated with arterial insufficiency tend to appear round or punched-out with scanty exudate. The wound bed may be covered with dry necrotic tissue involving structures such as muscle, tendon, and bone in the base. According to a systematic review of the evidence by Khan et al, ${ }^{24}$ cool skin (LR, 5.9; 95\% CI, 4.1-8.6) and pulse abnormalities (LR, 4.7; 95\% CI, 2.2-9.9) were considered the most useful indicators for lower extremity PAD.

\section{Ankle-brachial index}

Ankle-brachial index (ABI) is widely accepted as a simple, noninvasive, inexpensive, yet reliable measurement for PAD and cardiovascular risk assessment. According to a systematic review of eight international guidelines on screening for perfusion deficits, $\mathrm{ABI}$ was unanimously recommended as the primary diagnostic tool for PAD in the case of clinical suspicion based on symptoms and clinical findings. ${ }^{25}$ However, international studies indicate that screening is rarely performed in the primary care setting. ${ }^{26,27}$ The PAD awareness, risk, and treatment: new resources for survival study identified several barriers to the adoption of screening using $\mathrm{ABI}$ in primary care settings, including time constraints, reimbursement, staff availability, and staff training. ${ }^{27}$ The need to raise awareness and establish screening for PAD in the practice community is apparent.

ABI measurement can easily be obtained by any trained health care professional with a blood pressure cuff and a Doppler ultrasonic sensor in 10-15 minutes. To ensure accurate measurement, the following instructions are recommended:

1) Ask patients to recline and rest for 5-10 minutes in a supine position. 2) Measure systolic blood pressure in both arms and in both ankles from the dorsalis pedis and posterior tibial arteries. 3) Choose appropriate cuff size with cuff width approximately $20 \%$ larger than the limb diameter. 4) Place the blood pressure cuff approximately $2-3 \mathrm{~cm}$ above the medial malleolus. 5) Locate and listen to the pulse signal. Normal pulse generates three arterial components or triphasic signals. Stenosis is associated with monophasic sounds. 6) Inflate the cuff to at least $20 \mathrm{mmHg}$ beyond the calibration where the pulse signal disappears. 7) Slowly deflate the cuff until the signal returns, concordant with the measurement of systolic pressure for that vessel.

$\mathrm{ABI}$ is defined as the ratio of the highest ankle systolic blood pressure divided by the highest brachial systolic blood pressure. In case of possible subclavian artery stenosis that renders falsely low blood pressure, the higher of the two brachial pressures is recommended as the denominator for the calculation. The American College of Cardiology Foundation/American Heart Association Task Force 2011 guidelines define normal values between 1.0 and 1.4. ${ }^{1} \mathrm{An} \mathrm{ABI}$ of less than 0.9 is diagnostic for PAD; the lower values indicate more severe PAD. The values higher than 1.4 suggest that the arterial walls are calcified and cannot be compressed, as may be the case in some patients with diabetes or end-stage renal disease with medial calcinosis. A recent meta-analysis of eight studies comprising a total of 2,043 patients documented a high level of specificity $(83.3 \%-99.0 \%)$ and accuracy $(72.1 \%-89.2 \%)$ for an $\mathrm{ABI} \leq 0.90$ in detecting $\geq 50 \%$ stenosis as identified by other imaging methods, including angiography. ${ }^{28}$ However, the levels of sensitivity were less optimal (15\%-79\%) due to falsely elevated ABI that occurs when blood vessels are noncompressible. Exercise promotes vasodilation, leading to a drop in ankle blood pressure. To augment accuracy, ABI could be measured immediately after exercise, especially among individuals in whom PAD is suspected according to clinical presentation despite a normal $\mathrm{ABI}$ at rest (Table 1).

\section{Toe-brachial index}

Recognizing the limitation of ABI to establish the diagnosis of lower extremity PAD due to incompressible vessels, toe-brachial index (TBI) has been proposed as a reliable alternative means since toe vessels are less susceptible to calcification. The TransAtlantic Inter-Society Consensus for the Management of Peripheral Arterial Disease (TASC II) considered absolute toe pressure of $<30-50 \mathrm{mmHg}$ or a TBI $<0.70$ as an abnormal finding, ${ }^{29}$ although the normal lower limits of TBI could range from 0.49 to 0.74 according to a recent review of the literature. ${ }^{30}$ Previous studies demonstrate reliability of the measurement of toe pressures in patients with diabetes and varying severity of PAD with intraclass correlations ranging from 0.77 to 0.99 in intrarater 
reliability and 0.85 to 0.93 in interrater reliability. ${ }^{31-33}$ Using values of less than $0.6-0.75$ as diagnostic criteria, the TBI has a sensitivity of $90 \%-100 \%$, specificity of $65 \%-100 \%$, PPV of $47 \%-100 \%$, and NPV of $96 \%-100 \%$ for detecting peripheral artery disease (PAD) as identified by other imaging techniques (Table 1). ${ }^{30}$

\section{Transcutaneous oxygen pressure $\left(\mathrm{TcPO}_{2}\right)$}

Transcutaneous oxygen pressures are measured by placing a heated probe $\left(44^{\circ} \mathrm{C}\right)$ against the skin eliciting vasodilation and a local reactive hyperthermia. The probe measures oxygen that is released from red blood cells and diffuses through the epidermis. Byrne et al compared transcutaneous oxygen measurement with angiography. ${ }^{34} \mathrm{TcPO}_{2}$ had a sensitivity of $77 \%$ and specificity of $100 \%$ in detecting the presence of arterial disease at rest; both sensitivity and specificity improved to $100 \%$ after exercise (Table 1). The normal $\mathrm{TcPO}_{2}$ values are greater than $55 \mathrm{mmHg}$, and wound healing could be significantly impaired if the value drops to $<30 \mathrm{mmHg}$. $\mathrm{TcPO}_{2}$ is a good predictor of wound healing with an accuracy rate of $83 \% .{ }^{35}$ Of note, $\mathrm{TcPO}_{2}$ can be affected by oxygen uptake in the respiratory system and oxygen transport by the availability of hemoglobin and the function of the circulatory system.

\section{Skin perfusion pressure}

Skin perfusion pressure (SPP) is a noninvasive test using a laser Doppler to evaluate post-occlusive reactive hyperemia and determine the pressure that is required for restoring microcirculatory blood flow following a controlled release of occlusion (underneath the blood pressure cuff). Unlike ABI, SPP is not affected by conditions such as arterial wall calcification. SPP has been found to be significantly correlated with ABP, TBP, and TcPO2 $(r=0.75,0.85$, and 0.62 , respectively; all $P<0.0001) .{ }^{36}$ In a study of 113 patients with critical limb ischemia (123 limbs) who had undergone endovascular therapy, SPP of $30 \mathrm{mmHg}$ was useful for predicting wound heal with a sensitivity of $81.4 \%$ and a specificity of $69.2 \%$. Patients with SPP values of over $30 \mathrm{mmHg}$ after endovascular therapy achieved a $90.8 \%$ healing rate compared with 50\% in those having SPP values less than $30 \mathrm{mmHg} .{ }^{37}$ In another study of 100 patients with chronic extremity wounds, SPP values $\geq 30 \mathrm{mmHg}$ were highly sensitive $(89.7 \%$; 95\% CI,

Table I Summary of common bedside perfusion assessment techniques

\begin{tabular}{|c|c|c|c|}
\hline Test & Range & Evidence & Comments \\
\hline Palpable pedal pulse (PPP) & $80 \mathrm{mmHg}$ & $\begin{array}{l}\text { Absent or reduced pedal pulses increases the likelihood } \\
\text { of PAD (LR, } 4.70 ; 95 \% \mathrm{Cl}, 2.20-9.90 \text {; } \\
P<0.00 \text { I for heterogeneity). }{ }^{24} \\
\text { PPP compared to color duplex imaging: patients } \\
\text { with diabetes and PAD, sensitivity }=81 \% \text {, } \\
\text { specificity }=56 \% \text {, and PPV }=42 \%^{25}\end{array}$ & PPP can be affected by edema \\
\hline$A B I$ & $>0.5$ and $<1.4$ & $\begin{array}{l}\text { Using imaging techniques as reference tests, } A B I \text { is } \\
\text { able to detect PAD with sensitivity }=15 \%-79 \% \\
\text { and specificity }=83.3 \%-99 \% .^{54} \\
A B I \text { compared to color duplex imaging: } \\
\text { patients with diabetes and PAD, sensitivity }=53 \% \text {, } \\
\text { specificity }=95 \% \text {, and PPV }=80 \% 25 \\
\text { Audible signals: sensitivity }=42.8 \% \text {, specificity }=97.5 \% \text {, } \\
N P V=94.10 \% \text {, PPV }=65.22 \% \text {, positive likelihood ratio } \\
=I 7.52 \text {, and negative likelihood ratio }=0.59^{55}\end{array}$ & $\begin{array}{l}\text { False elevation in patients with calcified } \\
\text { vessels }{ }^{26} \\
\text { ABI-TBI index dropped if ABI was } 1.4^{27} \\
\text { Cuff inflation can be painful }\end{array}$ \\
\hline $\mathrm{TcPO}_{2}$ & $>30 \mathrm{mmHg}$ & $\begin{array}{l}\text { Below the knee, values of }<30 \mathrm{mmHg} \text { predict the } \\
\text { need for above the ankle amputation in diabetic } \\
\text { patients; sensitivity }=77 \% \text { and specificity }=83 \% \text { ' } \\
>30 \mathrm{mmHg} \text { predicts healing of DFU; sensitivity }=15 \% \text {, } \\
\text { specificity }=97 \% \text {, PPV }=79 \% \text {, and } \mathrm{NPV}=94 \%{ }^{28}\end{array}$ & $\begin{array}{l}\text { Accuracy of the test can be affected by } \\
\text { the presence of edema, dry flaky skin, } \\
\text { maceration, callused or plantar skin, and } \\
\text { cellulitis } \\
\text { This method does not measure oxygen } \\
\text { tension within the wound } \\
\text { A time-consuming test }\end{array}$ \\
\hline TBI & $0.6-0.75$ & $\begin{array}{l}\text { Sensitivity }=90 \%-100 \% \text {, specificity }=65 \%-100 \% \text {, } \\
\text { PPV }=47 \%-100 \% \text {, and NPV }=96 \%-100 \%\end{array}$ & $\begin{array}{l}\text { Large toe is of a small caliber without a } \\
\text { fully developed adventitial layer to allow } \\
\text { circumferential calcium deposits } \\
\text { Cannot be calibrated with previous toe } \\
\text { amputation }\end{array}$ \\
\hline
\end{tabular}

Abbreviations: PPP, palpable pedal pulse; PAD, peripheral artery disease; LR, likelihood ratio; $\mathrm{Cl}$, confidence interval; PPV, positive predictive value; $\mathrm{ABI}$, ankle brachial index; $\mathrm{ABI}$, ankle-brachial index; $\mathrm{NPV}$, negative predictive value; $\mathrm{TBI}$, toe-brachial index; $\mathrm{TcPO}_{2}$, transcutaneous oxygen tension; $\mathrm{DFU}$, diabetic foot ulcer. 
81-95) but non-specific (38.5\%; 95\% CI, 14-68) for the prediction of wound healing. ${ }^{38}$ The calculated PPV was $90.7 \%$ (95\% CI, 82-96) and NPV was 35.7 (95\% CI, 13-65). The accuracy of this test could be affected by movements, excess tremors, and incorrect placement of the sensor over bone or large vessels, or on nonblanching tissue.

\section{Near-infrared spectroscopy}

Near-infrared spectroscopy (NIRS) provides an estimation of changes in the concentrations of oxy- and deoxyhemoglobin in tissue ${ }^{39}$ Vardi and $\mathrm{Nini}^{40}$ reviewed 21 studies using NIRS for the evaluation of PAD. Compared to people without PAD, individuals with claudication symptoms exhibited a lower resaturation rate of oxyhemoglobin $\left(\mathrm{HbO}_{2}\right)$ and longer recovery times, after both walking and arterial occlusion. There is evidence that half time of recovery to baseline values $\left(T_{50}\right)$ for participants with PAD was significantly longer than people without PAD. Sensitivity and specificity ranged from $50 \%$ to $80 \%$. NIRS is correlated with ABI.

\section{Hyperspectral imaging}

Hyperspectral imaging (HSI) involves using a spectral sensor to detect the wavelength of light reflected from red blood cells in the skin. ${ }^{39}$ Since there is a difference in the wavelengths of light absorbed and emitted by red blood cells with oxyhemoglobin or deoxyhemoglobin, HSI can provide an accurate estimation for the levels of oxygenation and microvascular supply. It is desirable to have high levels of both oxyhemoglobin and deoxyhemoglobin that correlate with potential for wounds to heal. ${ }^{41}$ HSI is recognized as a valuable diagnostic tool to predict wound healing with reported sensitivity $86 \%-93 \%$, specificity $86 \%-88 \%$, PPV 93\%-96\%, and NPV 86\% ${ }^{41,42}$ Traditional contrast-based vascular imaging modalities are designed to confirm the diagnosis of PAD and to potentially plan for an intervention. These include conventional digital subtraction angiography (DSA), magnetic resonance angiography (MRA), and computed tomographic angiography (CTA). These investigations identify anatomic flow limiting stenoses/occlusions in large-, medium-, and small-sized arteries and allow surgeons and interventionalists to target revascularization with angioplasty/stent, endarterectomy, or bypass to improve wound perfusion. In general, the least diseased runoff artery is selected for revascularization based on the assumption that it could provide uninterrupted blood flow to the foot. ${ }^{43}$ While the majority of the procedures are technically successful, wound perfusion remains inadequate to support healing. ${ }^{44}$ More recently, the concept of angiosome-driven revascularization has challenged traditional thinking by suggesting that procedures should be directed to restore maximal blood flow to the tissue region where the wound is located. ${ }^{45}$ In the future, anatomic-based imaging studies may therefore need to be supplemented by the tissue perfusion studies such as the ones outlined in this document to improve wound-healing rates.

\section{Digital subtraction angiography}

Contrast-based imaging techniques and modalities such as CTA are often selected as the first-line investigation for PAD due to ease of accessibility, and rapidity with which results are available; conventional angiography remains the true gold standard for challenging cases. DSA offers precise imaging of even the most distal vasculature of the limb. Direct arterial access also permits the unique opportunity for immediate therapeutic interventions such as angioplasty or stenting. The risk of contrastinduced nephropathy in patients with preexisting renal insufficiency can be overcome by substituting iodinated contrast with carbon dioxide $\left(\mathrm{CO}_{2}\right) \cdot \mathrm{CO}_{2}$ can be used as a contrast agent and still provides high-quality images for interpretation.

\section{Magnetic resonance angiography}

MRA is a noninvasive technique that applies magnetic fields and radio waves to produce images of the blood vessels and perfusion patterns without any ionizing radiation or nephrotoxic contrasts. Klein et $\mathrm{al}^{46}$ compared MRA with DSA for the evaluation of crural arteries in 15 patients prior to free vascularized fibular flap transfer procedure. Results indicated a substantial agreement of stenosis severity scores between the two imaging techniques with Cohen's kappa of 0.64 . The sensitivity of MRA to detect a stenosis compared with that of DSA was 79\% (95\% CI, 60-91) and the specificity was $98 \%$ (95\% CI, 97-99). In a meta-analysis that involved 1,022 patients with known or suspected PAD of the lower extremities, the sensitivity of contrast-enhanced MRA was $94.7 \%$ (95\% CI, 92.1\%-96.4\%) and the specificity was $95.6 \%$ (95\% CI, 94.0\%-96.8\%) for diagnosing segmental steno-occlusions. ${ }^{47}$ MRA was able to provide correct assessment in $95.3 \%$ of the studied arterial segments. Limitations to MRA include length of time required to complete studies, pro-arterial imaging may be obscured by venous artifact, and concerns over nephrogenic systemic fibrosis when gadolinium is used in patients with renal impairment. Conventional MRA studies may be enhanced in the future with techniques to provide information on 
skeletal muscle perfusion, such as arterial spin labeling, blood oxygen level-dependent MRI, and first-pass dynamic contrast-enhanced MRI. ${ }^{48}$

\section{CTA}

CTA continues to be one of the most commonly used contrast-based imaging modalities in the investigation of lower extremity peripheral vascular disease. Within a few minutes, high-resolution images of the lower extremity arterial tree from the aorta to pedal vessels can be performed. ${ }^{49}$ Drawbacks of CTA include the use of both ionizing radiation (potential cancer risk) and iodinated contrast with the potential for contrast-induced nephropathy. ${ }^{50}$ Heavily calcified tibial vessels may pose problems for interpretation and lead to alternative studies being required to provide an accurate representation of the vasculature. New technologies such as single-photon emission computed tomography/computed tomography (CT) and positron emission tomography/CT seek to enhance the utility of CT scanning by adding a physiologic assessment of tissues. The addition of molecular imaging to traditional CT scans will allow for the highresolution anatomic images of $\mathrm{CT}$ scan to be enhanced with direct visualization of active areas of inflammation or infection. ${ }^{51}$ This information can play a key role in directing wound care.

\section{Indocyanine green angiography}

Indocyanine green (ICG) is a fluorescent dye that binds to plasma proteins and remains predominantly in the intravascular space until it is excreted by the hepatobiliary system. ICG is activated and illuminated by near-infrared light (between $700 \mathrm{~nm}$ and $1,000 \mathrm{~nm}$ ) that penetrates at least $3 \mathrm{~mm}$ below the surface of the skin. Subdermal perfusion can then be measured and expressed quantitatively in terms of fluorescence intensity in pixels, the time to maximum intensity (perfusion index), and the time from fluorescence onset to half the maximum intensity $\left(T_{1 / 2}\right)$. In a study that evaluated 22 limbs in 16 patients with PAD using indocyanine green angiography (ICGA), $T_{1 / 2}$ for more than 10 seconds was significantly correlated with an $\mathrm{ABI}$ value of $<0.7$ (sensitivity: 0.85, specificity: 1.0). ${ }^{52}$ According to another study of 30 patients with symptomatic PAD, perfusion index measure by ICGA was significantly related to collateral circulation in the lower extremities $(P=0.003)$. A receiver operating characteristic curve analysis for the perfusion index revealed a positive LR of 6.00 and a negative LR of 0.00 with an area under the curve of 0.949 to discriminate critical and non-critical PAD. ${ }^{53}$

\section{Conclusion}

The complexity of healing depends on many intrinsic and extrinsic factors, which regulate the complex biochemical and cellular events that culminate in closure of a wound with fibrotic scar tissue. Unlike acute wounds, chronic wounds, such as pressure ulcers, venous leg ulcers, and diabetic foot ulcers, do not always follow predictable temporal overlapping phases of healing due to inadequate tissue perfusion. Chronic or prolonged wound hypoxia is a key factor in the development and poor prognosis of chronic wounds. When oxygen availability to a wound is reduced by hypoperfusion from macrovascular arterial disease, microvascular failure, local edema, or infection, wound healing is invariably impaired. A systematic, multi-faceted, and personalized health care approach is required for optimal wound care management and healing outcomes. Careful attention should also be made to identify underlying diseases and lifestyle and exogenous factors that may be contributing to poor wound perfusion and healing outcomes in order to reverse and correct their deleterious effects. This proactive approach to institute early treatment based on quality clinical assessment may prevent or delay progression of the vascular disease, reduce the risk of further cardiovascular complications, ameliorate related symptoms, improve wound healing outcomes, minimize the risk of longterm disability, and improve overall quality of life.

\section{Funding}

The authors did not receive any financial support in preparation of this manuscript.

\section{Disclosure}

The authors have declared no conflicts of interest.

\section{References}

1. Rooke TW, Hirsch AT, Misra S, et al; Society for Cardiovascular Angiography and Interventions; Society of Interventional Radiology; Society for Vascular Medicine; Society for Vascular Surgery. 2011 ACCF/AHA Focused update of the guideline for the management of patients with peripheral artery disease (updating the 2005 guideline): a report of the American College of Cardiology Foundation/American Heart Association Task Force on Practice Guidelines. J Am Coll Cardiol. 2011;58:2020-2045.

2. Woo KY. Trends in wound management. Adv Skin Wound Care. 2013; 26(12):538-541.

3. Woo KY, Krasner DL, Kennedy B, Wardle D, Moir O. Palliative wound care management strategies for palliative patients and their circles of care. Adv Skin Wound Care. 2015;28(3):130-140.

4. Schreml S, Szeimies RM, Prantl L, Karrer S, Landthaler M, Babilas P. Oxygen in acute and chronic wound healing. Br J Dermatol. 2010; 163(2):257-268.

5. Bao P, Kodra A, Tomic-Canic M, Golinko MS, Ehrlich HP, Brem H. The role of vascular endothelial growth factor in wound healing. J Surg Res. 2009;153(2):347-358. 
6. Eisenbud DE. Oxygen in wound healing: nutrient, antibiotic, signaling molecule, and therapeutic agent. Clin Plast Surg. 2012;39(3):293-310.

7. Gordillo GM, Sen CK. Revisiting the essential role of oxygen in wound healing. Am J Surg. 2003;186(3):259-263.

8. Hopf HW, Rollins MD. Wounds: an overview of the role of oxygen. Antioxid Redox Signal. 2007;9(8):1183-1192.

9. Hunt TK, Ellison EC, Sen CK. Oxygen: at the foundation of wound healing - introduction. World J Surg. 2004;28:291-293.

10. Sen CK. Wound healing essentials: let there be oxygen. Wound Repair and Regen. 2009;17(1):1-18.

11. Sibbald RG, Woo KY, Queen D. Wound bed preparation and oxygen balance - a new component? Int Wound J. 2007;4(Suppl 3):9-17.

12. Woo KY, Coutts PM, Sibbald RG. Continuous topical oxygen for the treatment of chronic wounds: a pilot study. Adv Skin Wound Care. 2012; 25(12):543-547.

13. Guo S, DiPietro LA. Factors affecting wound healing. J Dent Res. 2010; 89(3):219-229.

14. Tandara AA, Mustoe TA. Oxygen in wound healing - more than a nutrient. World J Surg. 2004;28(3):294-300.

15. Heng MC, Harker J, Csathy G, et al. Angiogenesis in necrotic ulcers treated with hyperbaric oxygen. Ostomy Wound Manage. 2000;46 (18-28):30-32.

16. Hakim EW, Heitzman J. Wound management in the presence of peripheral arterial disease. Top Geriatr Rehabil. 2013;29(3): 187-194.

17. Rosamond W, Flegal K, Furie K, et al; for the American Heart Association Statistics Committee and Stroke Statistics Subcommittee. Heart disease and stroke statistics - 2008 update: a report from the American Heart Association Statistics Committee and Stroke Statistics Subcommittee. Circulation. 2008;117:e25-e146.

18. Rodriguez PG, Felix FN, Woodley DT, Shim EK. The role of oxygen in wound healing: a review of the literature. Dermatol Surg. 2008;34(9): 1159-1169.

19. Jensen JA, Goodson WH, Hopf HW, Hunt TK. Cigarette smoking decreases tissue oxygen. Arch Surg. 1991;126(9):1131-1134.

20. Lovell M, Harris K, Forbes T, et al. Peripheral arterial disease: lack of awareness in Canada. Can J Cardiol. 2009;25(1):39-45.

21. Audat G, Harbonnier M, Ouedraogo N, Leftheriotis G, Abraham P. Comparison of reported symptoms to those produced by treadmill testing in patients with claudication suspected of arterial origin. Int Angiol. 2014;33(4):379-383.

22. Spertus J, Jones P, Poler S, Rocha-Singh K. The peripheral artery questionnaire: a new disease-specific health status measure for patients with peripheral arterial disease. Am Heart J. 2004;147(2):301-308.

23. Woo KY, Botros M, Kuhnke J, Evans R, Alavi A. Best practices for the management of foot ulcers in people with diabetes. Adv Skin Wound Care. 2013;26(11):512-524.

24. Khan NA, Rahim SA, Anand SA, Simel DL, Panju A. Does the clinical examination predict lower extremity peripheral arterial disease. JAMA. 2006;295(5):536-546.

25. Mohler ER 3rd, Treat-Jacobson D, Reilly MP, et al. Utility and barriers to performance of the ankle-brachial index in primary care practice. Vasc Med. 2004;9:253-260.

26. Ferket BS, Spronk S, Colkesen EB, Hunink MG. Systematic review of guidelines on peripheral artery disease screening. Am J Med. 2012;125(2): 198-208.

27. Hirsch AT, Hiatt WR. PARTNERS Steering Committee. PAD awareness, risk, and treatment: new resources for survival - the USA PARTNERS program. Vasc Med. 2001;6(3 Suppl):9-12.

28. Dachun Xu, Jue LI, Liling Zou, et al. Sensitivity and specificity of the ankle - brachial index to diagnose peripheral artery disease: a structured review. Vasc Med. 2010;15(5):361-369.

29. Norgren L, Hiatt WR, Dormandy JA, et al. Inter-society consensus for the management of peripheral arterial disease (TASC II). Eur J Vasc Endovasc Surg. 2007;33(Suppl 1):S1-S75.

30. Høyer C, Sandermann J, Petersen LJ. The toe-brachial index in the diagnosis of peripheral arterial disease. J Vasc Surg. 2013;58(1): 231-238.
31. Brooks B, Dean R, Patel S, Wu B, Molyneaux L, Yue DK. TBI or not TBI: that is the question. Is it better to measure toe pressure than ankle pressure in diabetic patients? Diabet Med. 2001;18:528-532.

32. Suominen V, Rantanen T, Venermo M, Saarinen J, Salenius J. Prevalence and risk factors of PAD among patients with elevated ABI. Eur J Vasc Endovasc Surg. 2008;35:709-714.

33. Sahli D, Svensson M, Lidgren J, Ojbrandt K, Eriksson JW. Evaluation of simple non-invasive techniques for assessment of lower extremity arterial disease. Clin Physiol Funct Imaging. 2005;25:129-134.

34. Byrne P, Provan JL, Ameli FM, Jones DP. The use of transcutaneous oxygen tension measurements in the diagnosis of peripheral vascular insufficiency. Ann Surg. 1984;200(2):159.

35. Padberg FT, Back TL, Thompson PN, Hobson RW 2nd. Transcutaneous oxygen $\left(\mathrm{TcPO}_{2}\right)$ estimates probability of healing in the ischemic extremity. J Surg Res. 1996;60(2):365-369.

36. Yamada T, Ohta T, Ishibashi H, et al. Clinical reliability and utility of skin perfusion pressure measurement in ischemic limbs - comparison with other noninvasive diagnostic methods. J Vasc Surg. 2008;47(2): 318-323.

37. Utsunomiya M, Nakamura M, Nagashima Y, Sugi K. Predictive value of skin perfusion pressure after endovascular therapy for wound healing in critical limb ischemia. $J$ Endovasc Ther. 2014;21(5):662-670.

38. Lo T, Sample R, Moore P, Gold P. Prediction of wound healing outcome using skin perfusion pressure and transcutaneous oximetry. Wounds. 2009;21(11):310-316.

39. Manfredini F, Malagoni AM, Felisatti M, et al. A dynamic objective evaluation of peripheral arterial disease by near-infrared spectroscopy. Eur J Vasc Endovasc Surg. 2009;38(4):441-448.

40. Vardi M, Nini A. Near-infrared spectroscopy for evaluation of peripheral vascular disease. A systematic review of literature. Eur JVasc Endovasc Surg. 2008;35(1):68-74.

41. Khaodhiar L, Dinh T, Schomacker KT, et al. The use of medical hyperspectral technology to evaluate microcirculatory changes in diabetic foot ulcers and to predict clinical outcomes. Diabetes Care. 2007;30(4):903-910.

42. Nouvong A, Hoogwerf B, Mohler E, Davis B, Tajaddini A, Medenilla E. Evaluation of diabetic foot ulcer healing with hyperspectral imaging of oxyhemoglobin and deoxyhemoglobin. Diabetes Care. 2009;32(11):2056-2061.

43. Benitez E, Brandon J, Sumpio JC, Sumpio BE. Contemporary assessment of foot perfusion in patients with critical limb ischemia. Semin Vasc Surg. 2014;27(1):3-15.

44. Berceli SA, Chan AK, Pomposelli FB Jr, et al. Efficacy of dorsal pedal artery bypass in limb salvage for ischemic heel ulcers. J Vasc Surg. 1999;30:499-508.

45. Attinger CE, Evans KK, Bulan E, Blume P, Cooper P. Angiosomes of the foot and ankle and clinical implications for limb salvage: reconstruction, incisions, and revascularization. Plast Reconstr Surg. 2006; 117(Suppl):261S-293S.

46. Klein S, Van Lienden KP, Van`t Veer M, Smit JM, Werker PM. Evaluation of the lower limb vasculature before free fibula flap transfer. A prospective blinded comparison between magnetic resonance angiography and digital subtraction angiography. Microsurgery. 2013;33(7): 539-544.

47. Ouwendijk R, de Vries M, Stijnen T, et al; Program for the Assessment of Radiological Technology. Multicenter randomized controlled trial of the costs and effects of noninvasive diagnostic imaging in patients with peripheral arterial disease: the DIPAD trial. AJR Am J Roentgenol. 2008;190(5):1349-1357.

48. Brenner DJ, Hall EJ. Computed tomography - an increasing source of radiation exposure. $N$ Engl J Med. 2007;357(22):2277-2284.

49. Bar-Shalom R, Yefremov N, Guralnik L, et al. SPECT/CT using $67 \mathrm{Ga}$ and 111In-labeled leukocyte scintigraphy for diagnosis of infection. J Nucl Med. 2006;47(4):587-594.

50. Menke J, Larsen J. Meta-analysis: accuracy of contrast-enhanced magnetic resonance angiography for assessing steno-occlusions in peripheral arterial disease. Ann Intern Med. 2010;153(5):325-334. 
51. Klein S, Van Lienden KP, Van't Veer M, Smit JM, Werker PM. Evaluation of the lower limb vasculature before free fibula flap transfer. A prospective blinded comparison between magnetic resonance angiography and digital subtraction angiography. Microsurgery. 2013;33(7):539-544.

52. Igari K, Kudo T, Uchiyama H, Toyofuku T, Inoue Y. Intraarterial injection of indocyanine green for evaluation of peripheral blood circulation in patients with peripheral arterial disease. Ann Vasc Surg. 2014;28(5):1280-1285.

53. Zimmermann A, Roenneberg C, Reeps C, Wendorff H, Holzbach T, Eckstein HH. The determination of tissue perfusion and collateralization in peripheral arterial disease with indocyanine green fluorescence angiography. Clin Hemorheol Microcirc. 2012;50(3):157-166.
54. Xu D, Zou L, Xing Y, et al. Diagnostic value of ankle-brachial index in peripheral arterial disease: a meta-analysis. Can J Cardiol. 2013;29(4):492-498.

55. Alavi A, Sibbald RG, Nabavizadeh R, Valaei F, Coutts P, Mayer D. Audible handheld Doppler ultrasound determines reliable and inexpensive exclusion of significant peripheral arterial disease. Vascular. Epub 2015 Jan 27

\section{Publish your work in this journal}

Chronic Wound Care Management and Research is an international, peer reviewed, open access, online journal publishing original research, reviews, editorials, and commentaries on the causes and management of chronic wounds and the major issues related to chronic wound management. Topics also include chronic wounds as comorbidities to other conditions, patient adherence to therapy, and the economic burden of chronic wounds. The manuscript management system is completely online and includes a very quick and fair peer review system, which is all easy to use. Visit http://www.dovepress.com/testimonials.php to read real quotes from published authors.

Submit your manuscript here: http://www.dovepress.com/chronic-wound-care-management-and-research-journal 